\title{
Study of inertia weight parameter for boundary element inverse analysis to detect RC corrosion
}

\author{
Syarizal Fonna ${ }^{1, *}$, Gunawarman ${ }^{2}$, and Syifaul Huzni ${ }^{1}$ \\ ${ }^{1}$ Department of Mechanical and Industrial Engineering, Syiah Kuala University, Jl. Tgk. Syech \\ Abdul Rauf No. 7, Banda Aceh 23111, Indonesia \\ ${ }^{2}$ Department of Mechanical Engineering, Andalas University, Padang 25163, Indonesia
}

\begin{abstract}
This research studies the effect of an inconstant inertia weight $(W)$ parameter on boundary element inverse analysis (BEIA) to detect the corrosion of reinforcing steel/rebar in concrete. The boundary element method (BEM) and particle swarm optimization (PSO) were used in developing the BEIA. Several measured electrical potential data from halfcell potential measurements were taken as a reference when performing the BEIA. Numerical simulation of reinforced concrete with single corrosion showed that the use of inconstant $W$ with $W_{u p}=0.5$ and $W_{\text {low }} \leq 0.5$ did not affect the performance of the BEIA in corrosion detection. It was similar to the performance of the BEIA using a constant $W$ in a previous study $(0.25 \leq$ $W \leq 0.5)$. However, the corrosion can still be detected with acceptable accuracy; that is, with an error of less than $5 \%$. Hence, further research is needed to extend the study with $W_{u p}>0.5$ for an inconstant $W$.
\end{abstract}

\section{Introduction}

Corrosion is the degradation of metal due to interaction with its environment. Nowadays, it is the main cause of some structural failures, including those of reinforced concrete (RC) structures. Several media reports have described the failure of RC structures. Some of the structures that have collapsed due to corrosion are the Silver Bridge in America in 1967 [1], a toll road bridge in Canada in 2006 [2], Atlantis Water Adventure Taman Impian Jaya Ancol in Indonesia in 2011 [3], and the hallway inside the Indonesian Stock Exchange (BEI) building in 2018 [4]. Therefore, it is important to perform early detection of corrosion of rebar/reinforcing steel in concrete in order to avoid the premature failure of structures [5].

One of the most popular methods of monitoring corrosion of reinforcing steel in concrete is the half-cell potential mapping technique. ASTM C876 is used for the application and interpretation of the results of the method. Many researchers have reported the implementation of this method in the field [5-7]. However, some limitations of the method remain: the accuracy depends on the number of data [8], the method is laborious and timeconsuming [9], and it only shows the probability that corrosion will occur [10]. Hence, it is necessary to improve the method to reduce its limitations.

* Corresponding author: syarizal.fonna@unsyiah.ac.id 
One of the promising techniques to improve the performance of half-cell potential mapping is by implementing numerical analysis such as boundary element inverse analysis (BEIA). In the previous study, the boundary element method (BEM) and particle swarm optimization (PSO) were developed into BEIA [11]. BEIA uses measurement data such as the half-cell potential technique to detect rebar corrosion. It has shown promising capability to detect corrosion in a case study [12]. The influence of inertia weight $(W)$ on the performance of the method in detecting corrosion has also been studied $[11,13]$. However, these studies were limited to a constant $W$, while other studies recommended the use of inconstant $W$ [14]. Therefore, it is important to perform further investigations.

The aim of this study is to investigate the effect of inconstant $W$ (with $W_{u p}=0.5$ and $W_{\text {low }}$ $\leq 0.5$ ) on the performance of BEIA in detecting rebar corrosion in concrete. For this purpose, a simple RC structure with single rebar and corrosion was utilized as a case study.

\section{Development of BEIA}

BEIA has been developed in previous studies [11-13]. The developed BEIA was based on the boundary element method (BEM) and particle swarm optimization (PSO). BEM was used to calculate the potential distribution in the whole domain, while PSO was used to optimize the objective function in order to detect the location of the corrosion. The subsequent sections present the development of BEIA.

\subsection{Rebar corrosion model in concrete}

Corrosion of reinforcing steel in concrete can be modelled as shown in Figure 1. The concrete column only has single rebar and single corrosion. The corroding and non-corroding parts of the rebar are the anode and cathode, respectively. For the model, the electrical potential $(\phi)$ is governed by the Laplace equation for the $\mathrm{RC}$ domain $(\Omega)$. The Laplace equation is expressed by Equation (1) [11-13].

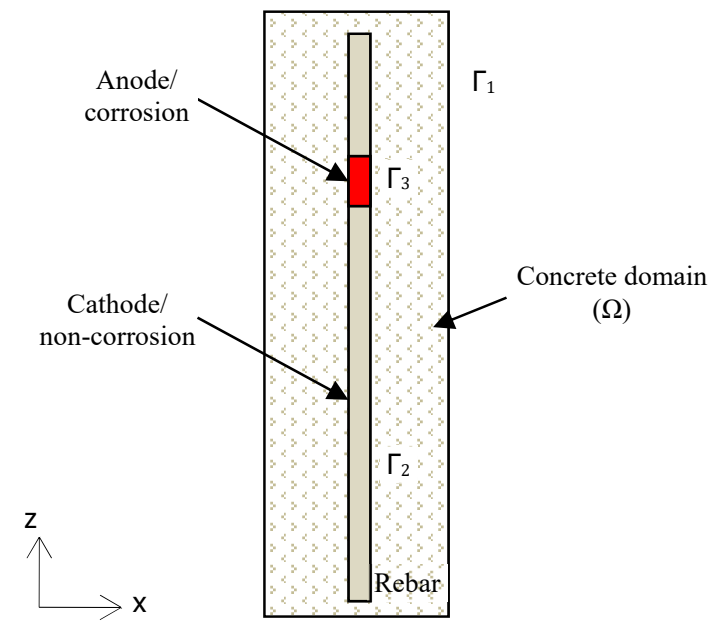

Fig. 1. Rebar corrosion model in a column of a concrete structure.

The current density $(i)$ and electrical potential $(\phi)$ can be related by Equation (2) for the domain [15]. In Equation (2), $\kappa$ is the domain conductivity, $\boldsymbol{n}$ is the outward normal unit, and $\partial / \partial \boldsymbol{n}$ is the derivative in the normal direction. 


$$
\begin{array}{ll}
\nabla^{2} \phi=0 & \text { in } \Omega \\
i=-\kappa \frac{\partial \phi}{\partial n} & \left(\mathrm{~A} / \mathrm{m}^{2}\right)
\end{array}
$$

Equations (3-5) represent the boundary conditions for the model in Figure 1. The boundary condition for the concrete surface $\left(\Gamma_{1}\right)$ is given by Equation (3). In this study, the current density $(i)$ was set equal to zero. This was because the concrete had low conductivity. The boundary conditions of the corroding and non-corroding parts of the rebar are represented by the polarization curves. The curves give the relationship between the electrical potentials $(\phi)$ and current density $(i)$, as expressed by Equation (4) for the cathode $\left(\Gamma_{2}\right)$ and Equation $(5)$ for the anode $\left(\Gamma_{3}\right)$ of the rebar [16].

$$
\begin{array}{lll}
i=i_{0} & \left(\mathrm{~A} / \mathrm{m}^{2}\right) & \text { on } \Gamma_{1} \\
\phi=-f_{c}(i) & (\mathrm{V}) & \text { on } \Gamma_{2} \\
\phi=-f_{a}(i) & (\mathrm{V}) & \text { on } \Gamma_{3}
\end{array}
$$

In order to solve the Laplace equation in Equation (1), BEM was used. A detailed procedure for formulating the BEM can be found in Reference [17]. By following the formulation procedure, the unknown values of $\phi$ and $i$ on the surface of the domain can be determined.

\subsection{Boundary element inverse analysis (BEIA)}

The BEIA technique was developed by combining BEM and PSO. Kennedy and Eberhart first introduced PSO in 1995, inspired by the social behaviour of flocking birds and schooling fish in search for food [14]. The developed BEIA has shown promise in detecting rebar corrosion as elaborated in previous works $[11,12]$. The algorithm of BEIA is shown in Figure 2. The procedure of the technique can be found in Reference [11]. In the technique, the term "particle" is used to indicate the candidate solutions.

In detecting the rebar corrosion, the technique optimizes the cost function $(\varepsilon)$ as given in Equation (6) $[9,11]$. The cost function is evaluated for each particle of the iteration. In the equation, $C$ is the location of rebar corrosion and $N$ is the number of measured electrical potential data inputted into the BEIA. $\phi$ and $\bar{\phi}$ are the electrical potential calculated by using BEM and measured electrical potentials found by using the half-cell potential meter, respectively. $\bar{\phi}_{\max }$ is the highest value of electrical potential among $N$ data.

$$
\varepsilon(C)=\sum_{l=1}^{N}\left[\left(\frac{\phi_{l}-\bar{\phi}_{l}}{\bar{\phi}_{\max }}\right)\right]^{2}
$$

In each iteration, the updated location and velocity of particles are based on the local and global best particles as given in Equations (7) and (8). For these equations, $X_{j+1}$ is the next particle location, $X_{j}$ is the current particle location, $V_{j+l}$ is the next particle velocity, $V_{j}$ is the current particle velocity, $W_{j}$ is the inertia weight, $a_{l}$ and $a_{2}$ are constants, $r_{l}$ and $r_{2}$ are random numbers $(0-1)$, pbest is the local best particle, gbest is the global best particle, and $j$ denotes the iteration.

In this study, the inertia weight $(W)$ was set to be inconstant. The values of $W$ change during each iteration according to Equation (9) [14]. The value of $W_{u p}$ used in the study was 0.5 and $W_{\text {low }} \leq 0.5$. These values are still in the range of the constant $W$ recommended by the previous study [11].

$$
X_{j+1}=X_{j}+V_{j+1}
$$




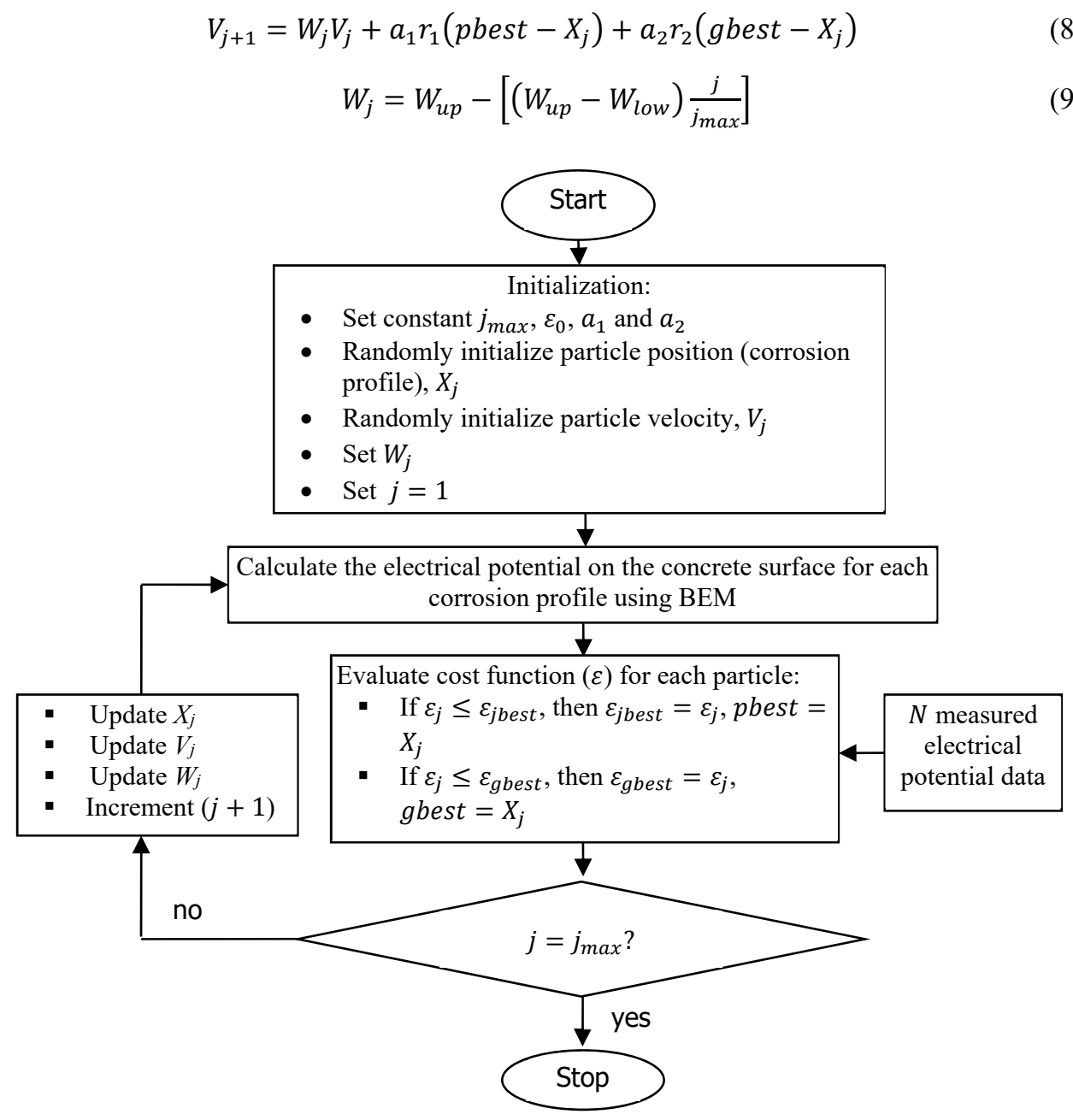

Fig. 2. Algorithm of developed BEIA which combines BEM and PSO.

\section{Simulation setup}

A simple column of RC was used to study the effect of the inconstant $W$ on the performance of the BEIA. The column has a single reinforcing steel with one corroding part as shown in Figure 3. The figure shows how the 3D model of the RC column (Figure 3a) was simplified into a 2D model (Figure $3 \mathrm{~b}$ ) for the simulation. In the figure, the length of the column and rebar were $70 \mathrm{~cm}$, the cover depth was $10 \mathrm{~cm}$, and the size of the corroded area was $2 \mathrm{~cm}$. The corrosion location (CL) was still unknown for the column and would be detected by the BEIA. 


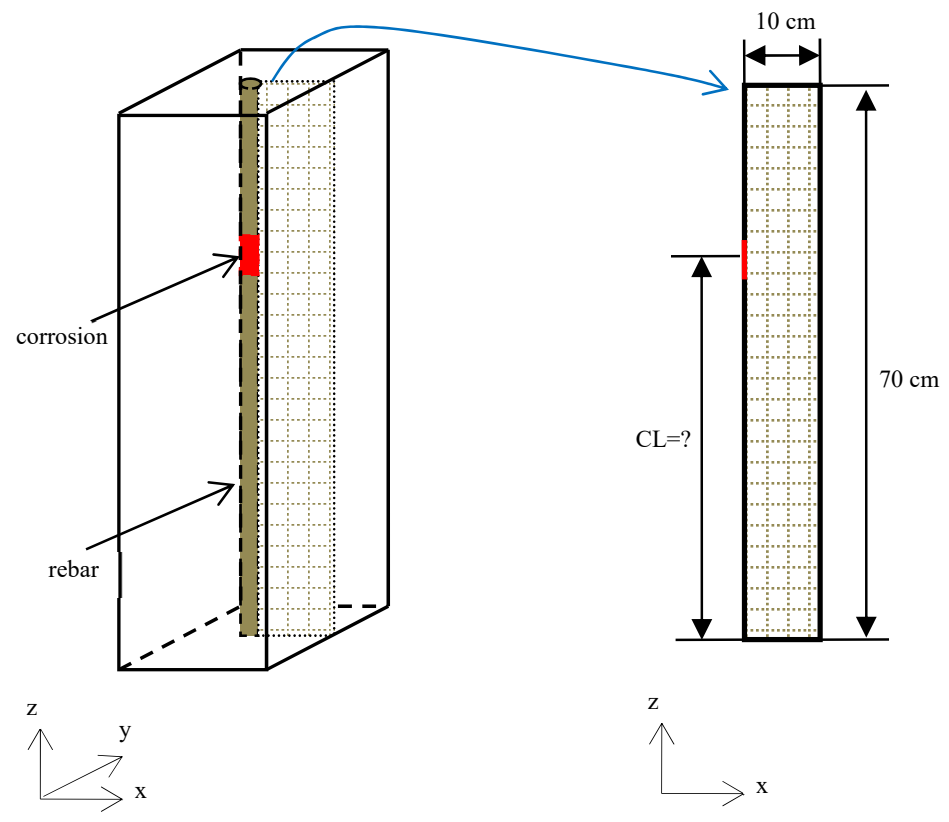

(a) 3D model

(b) $2 \mathrm{D}$ model

Fig. 3. RC column used in the study.
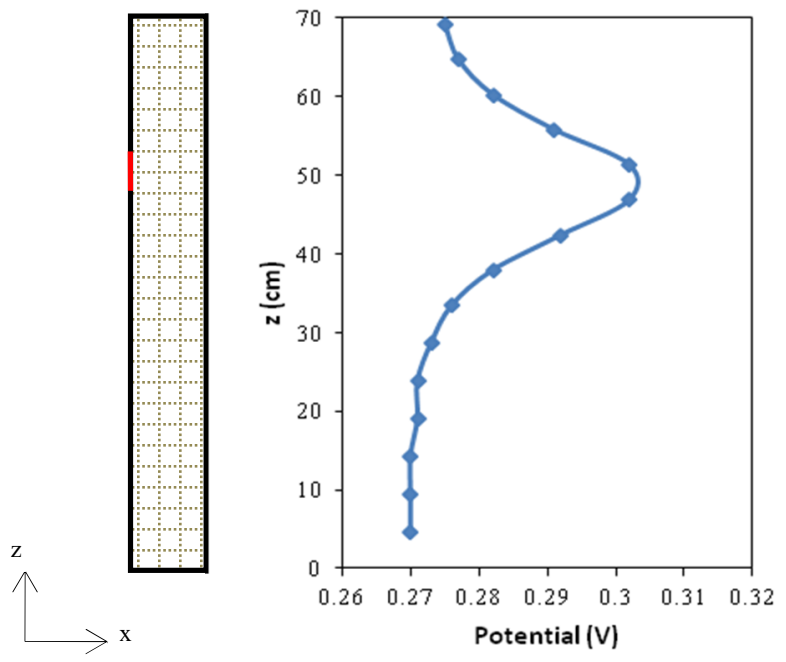

Fig. 4. Electrical potential on the concrete surface from BEM calculation used as measured electrical potential data in the BEIA.

$$
\begin{aligned}
& \phi_{a}=0.600-10 i \\
& \phi_{c}=0.270-10 i
\end{aligned}
$$

In order to run the BEIA, some measured electrical potential data that can be provided by half-cell potential measurements are needed. However, in this study, the measured electrical potentials were obtained from BEM simulation with the location of the corrosion set as $z=$ $50 \mathrm{~cm}$. The electrical potentials are shown in Figure 4. Moreover, five candidate solutions 
were used to study the effect of inconstant $W$ on the detection performance of the BEIA. The values of $W_{u p}$ and $W_{\text {low }}$ (to provide inconstant $W$ ) for the study are given in Table 1 . The constant parameters have also been set as $\kappa=0.007 \Omega^{-1} \cdot \mathrm{m}^{-1}, \varepsilon_{0} \leq 10^{-4}, a_{1}=a_{2}=0.5$, and $N=$ 15 for the simulation. For the boundary conditions of the anode and cathode, the polarization curves from Reference [16] were used and thus generated into Equations (9) and (10) [9] respectively. After all parameter and constants had been set, the BEIA was ready to be executed.

Table 1. The values of $\mathrm{W}_{\text {up }}$ and $\mathrm{W}_{\text {low }}$ for the simulation.

\begin{tabular}{|c|c|c|c|}
\hline No. & $\boldsymbol{W}_{\text {up }}$ & $\boldsymbol{W}_{\text {low }}$ & $\begin{array}{c}\text { Gradient of } \boldsymbol{W} \\
\text { during iteration }\end{array}$ \\
\hline 1 & 0.5 & 0.5 & 0 \\
\hline 2 & 0.5 & 0.2 & -0.015 \\
\hline 3 & 0.5 & 0.01 & -0.0245 \\
\hline
\end{tabular}

\section{Numerical simulation results and discussion}

The BEIA simulation results for the values of $W_{u p}$ and $W_{\text {low }}$ as given in Table 1 are shown in Figures 5, 6, and 7. Figure 5 shows that the value of $W$ was unchanged with increasing number of iterations or that $W$ was constant. Five particles were randomly distributed in the search space along the $z$-axis in the first iteration. Then, all particles moved to a certain position in the search space on increasing the number of iterations. All solution candidates (particles) remained in the same place from the 14th to the 20th iteration. This indicated that the location of the corrosion had already been detected and the average error with respect to the actual location of the corrosion was $0.26 \%$.

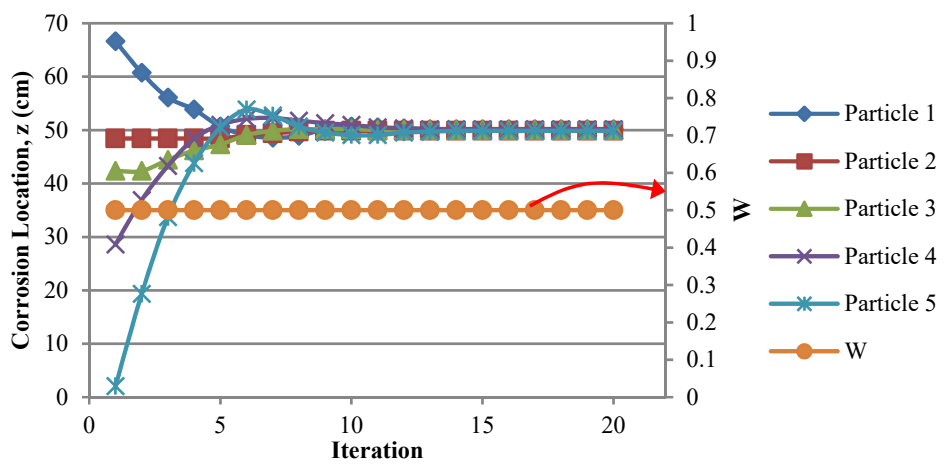

Fig. 5. The particle movement and the value of $W$ during iteration for $W_{u p}=0.5$ and $W_{\text {low }}=0.5$.

Figure 6 shows that the value of $W$ changed as the number of iterations increased or that $W$ was inconstant with a gradient of -0.015 . In the first iteration, five particles were also randomly distributed in the search space and moved to a certain position as the number of iterations increased. Then, all particles were located in the same place from the 11 th to the 20th iteration. This result shows that the location of the corrosion was detected with an average error of $0.46 \%$ with respect to the actual location of the corrosion. 


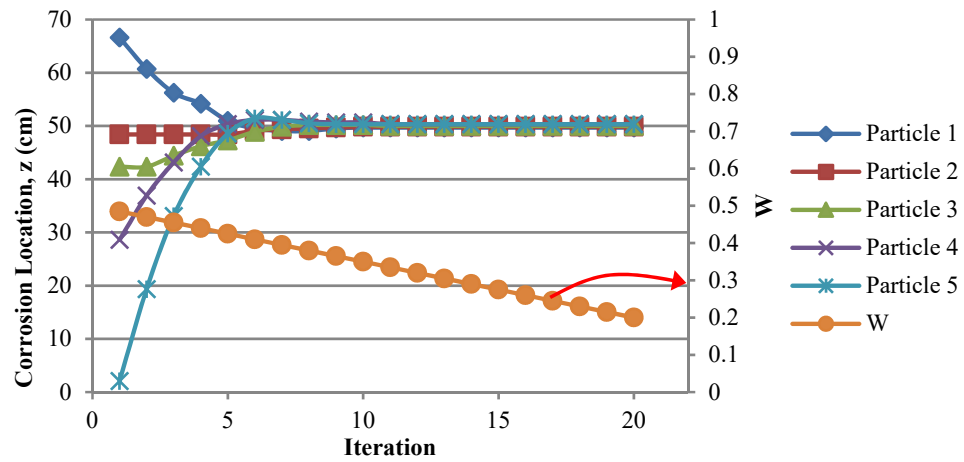

Fig. 6. The movement of particles and value of $W$ during iteration for $W_{u p}=0.5$ and $W_{\text {low }}=0.2$.

The value of $W$ was also inconstant with a gradient of -0.0245 as seen in Figure 7 . The five particles were also randomly distributed along the search space in the first iteration and displaced to a certain position when the number of iterations increased. Then, all particles were located in the same place from the 14 th to the 20 th iteration. This shows that the location of the corrosion was detected with an average error of $0.33 \%$ with respect to the actual location of the corrosion.

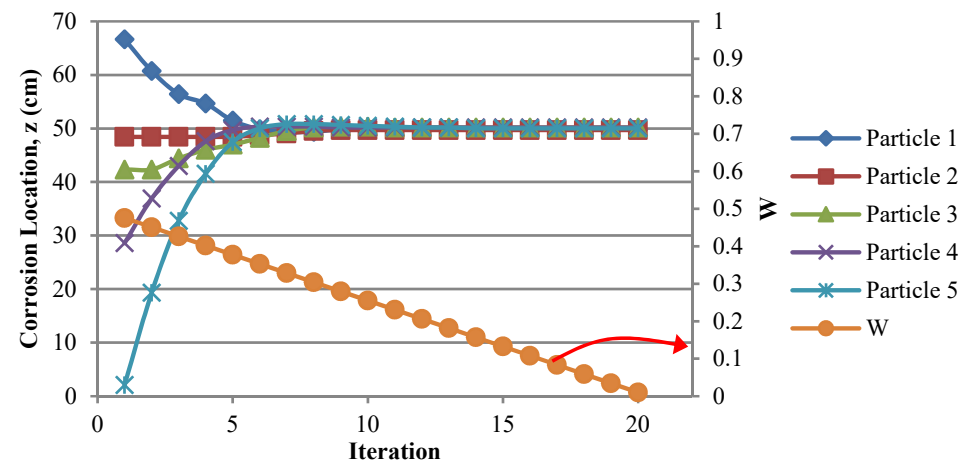

Fig. 7. The particles' movement and the value of $W$ during iteration for $W_{u p}=0.5$ and $W_{\text {low }}=0.01$.

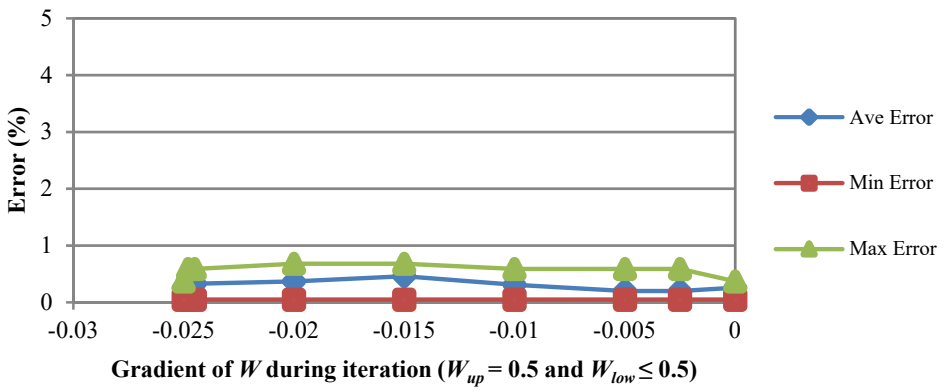

Fig. 8. The error in detecting actual corrosion for $W_{u p}=0.5$ and $W_{\text {low }} \leq 0.5$.

The simulation was continued for other gradients of $W$ and is summarized in Figure 8. The figure shows that the error with respect to the actual location of corrosion was $<5 \%$ for all gradients of $W$. This indicated that the accuracy of the BEIA in detecting the location of the corrosion was acceptable. Hence, the inconstant $W$ in the range recommended by the previous study [11] did not affect the performance of the BEIA when detecting corrosion. 


\section{Conclusions}

In this study, the effect of inconstant $W$ on BEIA when detecting rebar corrosion in concrete was explored. BEIA was developed by combining BEM and PSO. The numerical simulation results show that the inconstant $W$ with $W_{u p}=0.5$ and $W_{\text {low }} \leq 0.5$ did not influence the performance of the BEIA in detecting rebar corrosion. The accuracy was similar to the performance of the BEIA when using a constant $W$ in the previous study $(0.25 \leq W \leq 0.5)$; that is, the error with respect to the actual location of corrosion was less than $5 \%$. Therefore, it is important to conduct further research to study the effect of $W_{u p}>0.5$ for inconstant $W$.

The research was supported by Penelitian Pascadoktor No. 76/UN11.2/PP/SP3/2018, Direktorat Riset dan Pengabdian Masyarakat, Direktorat Jenderal Penguatan Riset dan Pengembangan, Ministry of Research, Technology and Higher Education, Republic of Indonesia

\section{References}

1. C. LeRose, West Virginia Historical Society Quarterly 15 (4) http://www.wvculture.org/history/wvhs/wvhs1504.html (2001)

2. CBC News, http://www.cbc.ca/news/canada/montreal/too-early-to-speculate-aboutoverpass-collapse-inquiry-head-1.618804 (2006)

3. Latief, http://megapolitan.kompas.com/read/2011/09/28/12185069/Struktur.Wahana. Atlantis.Dikaji.Ulang (2011)

4. Administrator, http://mediaindonesia.com/read/detail/141078-korosi-penyebab-selasarbei-runtuh (2018)

5. S. Fonna, M. Ridha, S. Huzni, W.A. Walid, T.D. Mulya, A.K. Ariffin, Proc. Eng. 171, 965-976 (2017)

6. T. Parthiban, R. Ravi, G.T. Parthiban, Adv. Eng. Softw. 37, 375-381 (2007)

7. V. Leelalerkiet, J.W. Kyung, M. Ohtsu, M. Yokota, Constr. Build. Mater. 18, 155-162 (2004)

8. H.W. Song and V. Saraswathy, Int. J. Electrochem. Sci. 2, 1-28 (2007)

9. M. Ridha, K. Amaya, S. Aoki, Corrosion 61, 784-791 (2005)

10. P. Marinier, O.B. Isgor, Nondestructive testing of materials and structure, ed. $\mathrm{O}$ Büyüköztürk et al. (RILEM Bookseries Springer-Verlag, 2013) 719-724

11. S. Fonna, S. Huzni, M. Ridha, A.K. Ariffin, Eng. Anal. Bound. Elem. 37, 585-593 (2013)

12. S. Fonna, Gunawarman, S. Huzni, A.K. Ariffin, Case Stud. Constr. Mater. 8, 292-298 (2018)

13. S. Fonna, M. Ridha, S. Huzni, A.K. Ariffin, Adv. Mater. Res. 686, 266-272 (2013)

14. K.E. Parsopoulos, M.N. Vrahatis, Particle swarm optimization and intelligence: Advances and applications (Information Science Reference, New York, 2010)

15. S. Fonna, I.M. Ibrahim, M. Ridha, S. Huzni, A.K. Ariffin, Int. J. Corros. 2016, 1-5 (2016)

16. H.G. Wheat, Z. Eliezer, Corrosion 41, 640-645 (1985)

17. C.A. Brebbia, J. Dominguez, Boundary elements - an introductory course (2nd ed. Computational Mechanic Publication/WIT Press, Southampton, 1998) 